\title{
KEEFEKTIFAN LAGU KREASI GURU DALAM MENINGKATKAN KEMAMPUAN SISWA UNTUK MENDESKRIPSIKAN BENDA
}

\author{
Ummiati Rauf ${ }^{1}$ \\ Munirah $^{2^{*}}$ \\ $\mathrm{Jam}^{\prime} \mathrm{an}^{3}$ \\ ${ }^{1}$ SDN 28 Bontomacinna Kabupaten Bulukumba, Bulukumba, Indonesia \\ ${ }^{2,3}$ Universitas Muhammadiyah Makassar, Indonesia \\ ummiatirauf5@gmail.com ${ }^{1)}$ \\ munirah@unismuh.ac.id ${ }^{2 *}$ \\ andi.jam'an@unismuh.ac.id ${ }^{3)}$
}

\begin{abstract}
Abstrak
Tujuan penelitian ini adalah untuk memperoleh, menganalisis, menginterpretasi dan menyajikan, serta melaporkan data mengenai (1) tingkat kemampuan mendeskripsikan benda sebelum pembelajaran menggunakan lagu kreasi guru siswa kelas I SDN 28 Bontomacinna Kabupaten Bulukumba. (2) tingkat kemampuan mendeskripsikan benda sesudah pembelajaran menggunakan lagu kreasi guru siswa kelas I SDN 28 Bontomacinna Kabupaten Bulukumba. (3) Efektif tidaknya pembelajaran menggunakan lagu kreasi guru dalam meningkatkan kemampuan mendeskripsikan benda siswa kelas I SDN 28 Bontomacinna Kabupaten Bulukumba. Jenis penelitian ini adalah penelitian survei dengan teknik eksperimen semu. Adapun populasi penelitian adalah seluruh siswa kelas I SDN 28 Bontomacinna Kabupaten Bulukumba tahun pelajaran 2020/2021. Populasi tersebut berjumlah 28 orang yang dengan teknik pengambilan sampel adalah total sampling. Hasil penelitian ini menunjukkan bahwa (1) Tingkat hasil belajar mendeskripsikan benda siswa Kelas I SDN 28 Bontomacinna Kabupaten Bulukumba sebelum menggunakan lagu kreasi adalah rata-rata 63,31 dalam rentangan nilai 10-100 dengan kategori sedang (2) Tingkat hasil belajar mendeskripsikan benda siswa kelas I Kelas I SDN 28 Bontomacinna Kabupaten Bulukumba sesudah menggunakan lagu kreasi adalah rata-rata 74,64 dalam rentangan nilai 10-100 dengan kategori tinggi (3) Pembelajaran menggunakan lagu kreasi guru efektif dalam meningkatkan kemampuan mendeskripsikan benda siswa kelas I SDN 28 Bontomacinna Kabupaten Bulukumba denganm nilai t Critical two-tail (stat: 11,75686525 > t Critical two-tail: 1,703288446) pada taraf signifikan 0,05 .
\end{abstract}

Kata kunci: Lagu kreasi guru, Mendeskripsikan benda

Published by:

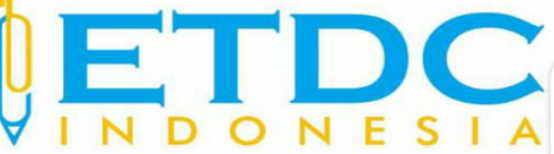

Copyright (C) 2021 The Author (s)

This article is licensed under CC BY 4.0 License

(cc) $\mathrm{BY}$ 


\section{KEEFEKTIFAN LAGU KREASI GURU DALAM MENINGKATKAN KEMAMPUAN SISWA UNTUK MENDESKRIPSIKAN BENDA}

\section{Pendahuluan}

Pembelajaran bahasa berfungsi meningkatkan keterampilan berbahasa, meningkatkan kemampuan berpikir, bernalar, serta meningkatkan daya intelektual (Silaswati et al., 2019; Khair, 2018). Pembelajaran bahasa Indonesia di SD bertujuan meningkatkan kemampuan siswa dalam berkomunikasi dengan benar, baik secara lisan maupun tertulis. Pembelajaran bahasa Indonesia diarahkan untuk meningkatkan kemampuan siswa berkomunikasi dalam bahasa Indonesia dengan baik dan benar, baik secara lisan maupun tulis,serta menumbuhkan apresiasi terhadap hasil karya kesusastraan manusia Indonesia. Komunikasi lisan mencakup keterampilan menyimak dan berbicara, sedangkan berkomunikasi tertulis mencakup keterampilan membaca dan menulis (Diari \& Putra, 2019; Anggraini, 2019).

Kurikulum 2013 yang sejalan dengan tujuan pembelajaran bahasa Indonesia, yakni agar siswa terampil berbahasa. Keterampilan berbahasa dibedakan dari empat macam, yaitu menyimak, berbicara, membaca, dan menulis. Keempat keterampilan berbahasa tersebut berkaitan antara satu dan yang lain. Masing-masing keterampilan berbahasa saling behubungan dan membangun satu kemahiran berbahasa yang memungkinkan seseorang dapat berkomunikasi, baik secara lisan maupun tulis.

Kenyataan di atas ditemukan pula, bahwa dalam pembelajaran keterampilan berbahasa, sesuai dengan namanya bertujuan untuk menumbuhkan dan mengembangkan keterampilan berbahasa siswa. Terampil berbahasa berarti terampil menyimak, terampil berbicara, terampil membaca, dan terampil menulis. Fungsi bahasa adalah sebagai alat komunikasi. Komunikasi dapat berwujud langsung dan tidak langsung. Standar kompetensi mata pelajaran bahasa Indonesia berorientasi pada hakikat pembelajaran bahasa, bahwa belajar bahasa adalah belajar berkomunikasi dan belajar sastra adalah belajar menghargai manusia dan nilai-nilai kemanusiaannya (Suwandi \& Rohmadi, 2013; Budiman, 2018; Eti, 2018). Demikian pula dengan standar kompetensi lintas kurikulum yang menekankan pada kecakapan untuk hidup dan belajar sepanjang hayat. Standar kompetensi lintas kurikulum ini meliputi kemampuan siswa untuk memilih, memadukan, dan menerapkan konsep-konsep, teknik-teknik, pola, struktur, dan hubungan.

Pembelajaran keterampilan berbahasa pada dasarnya merupakan upaya meningkatkan keterampilan menyimak, berbicara, membaca dan menulis yang fokus tujuan pembelajarannya 
dilaksanakan secara terpadu (Sumarwati, 2017; Sumarwati et al., 2019; Abidin et al., 2021). Untuk mendapatkan hasil belajar yang sesuai dengan tujuan pembelajaran bahasa, pembelajaran empat aspek keterampilan itu harus melalui proses pembelajaran yang strategis dan diperlukan perhatian serta pembinaan bahasa Indonesia secara bersinambungan, baik secara lisan maupun tulisan yang melalui pembiasaan untuk mempermahir keempat keterampilan berbahasa tersebut secara terpadu.

Berdasarkan uraian di atas, dapat dikatakan bahwa pembelajaran bahasa Indonesia hendaknya dilakukan secara terpadu dan tematik. Pembelajaran bahasa Indonesia tidak disajikan secara terpisah, tetapi disajikan dalam program rencana pembelajaran secara tematik dan penyajiannya bersifat terpadu pula. Keterpaduan pembelajaran keterampilan menyimak, berbicara, membaca, dan menulis dapat dilakukan dengan jalan memadukan keterampilan ini seperti (a) menyimak dan berbicara, (b) menyimak dan menulis, (c) berbicara dan menulis, dan (d) membaca dan menulis. Pembelajaran keterampilan terpadu antara membaca dan menulis di kelas awal merupakan suatu sistem dari suatu kegiatan yang menyeluruh dan terorganisasi, mulai dari proses pelaksanaan sampai pada evaluasi (Hum, 2015; Ahmad Susanto, 2016; Yaumi, 2016; Samsudin, 2012).

Pengamatan terhadap pelaksanaan kegiatan berbahasa di dalam kelas, pada tingkat SD, SMP, SMA, maupun di perguruan tinggi, kegiatan menyimak lebih sering terjadi daripada kegiatan membaca, berbicara, dan menulis. Lebih-lebih di dalam kelas yang mnyelenggarakan kegiatan belajar mengajar yang berfokus kepada guru dominasi aspek keterampilan menyimak saat dominan. Demikian pula halnya di dalam kelas yang menerapkan strategi belajar-mengajar yang memusatkan pada keterlibatan siswa secara aktif, aspek keterampilan menyimak juga masih banyak terjadi.

Dari uraian di atas, dapatlah dikatakan bahwa pembelajaran keterampilan berbahasa lebih banyak terpusat pada aspek keterampilan menyimak, padahal dalam kurikulum hal yang harus ditonjolkan pada anak adalah anak harus melakukan dan menghasilkan sesuatu. Hal ini dapat dilihat pada berubahnya aspek-aspek penilaian pada buku laporan pendidikan. Jika sebelumnya pada Kurikulum 2006 penilaian pelajaran bahasa Indonesia hanya terdiri dari satu komponen, maka pada kurikulum 2013 penilaian terdiri atas empat komponen yaitu menyimak, berbicara, membaca, dan menulis (Marhaeni, 2015; Nur'aini et al., 2015). Dengan adanya perubahan tersebut, guru dituntut untuk lebih kreatif dan inovatif serta berupaya menyajikan pengajaran bahasa yang utuh, yaitu sebuah pendekatan yang memandang menyimak, berbicara, membaca, dan menulis sebagai suatu bagian yang terpadu. Agar harapan tersebut dapat terwujud, maka para guru diharapkan, benar-benar memiliki kompetensi dalam menentukan 
strategi pembelajaran keterampilan berbahasa agar siswa lebih termotivasi dan bergairah dalam pembelajaran bahasa Indonesia.

Penyebab ketidakberhasilan pembelajaran menyimak, berbicara, membaca, dan menulis dalam mata pelajaran bahasa Indonesia disebabkan oleh pembelajaran masih berpusat pada guru, siswa kurang mendapat perhatian guru dalam menetapkan strategi dan penentuan metode pembelajaran yang tepat, serta sistem penilaiannya cenderung menekankan pada aspek kognitif, kurang menekankan pada aspek psikomotor atau keterampilan berbahasa (Susilo \& Ramdiati, 2019; Dewantara, 2012; Nurjanah \& Rahmawati, 2020). Padahal dalam standar kompetensi mata pelajaran bahasa Indonesia ini diharapkan.(1) peserta didik dapat mengembangkan potensinya sesuai dengan kemampuan, kebutuhan, dan minatnya, serta dapat menumbuhkan penghargaan terhadap hasil hanya kesastraan dan hasil intelektual bangsa sendiri. (2) guru dapat memusatkan perhatian kepada pengembangan kompetensi bahasa peserta didik dengan menyediakan berbagai kegiatan berbahasa dan sumber belajar. (3) guru lebih mandiri dan leluasa dalam menentukan bahan kebahasaan dan kesastraan sesuai dnegan kondisi lingkungan sekolah dan kemampuan peserta didiknya. (4) orang tua dan masyarakat secara aktif terlihat dalam pelaksanaan program kebahasaan dan kesastraan di sekolah. (5) sekolah dapat menyusun program pendidikan tentang kebahasaan dan kesastraan sesuai dengan keadaan peserta didik dan sumber belajar yang tersedia. (6) daerah dapat menentukan bahan dan sumber belajar kebahasaan dan kesastraan sesuai dengan kondisi dan kekhasan daerah dengan tetap memperhatikan kepentingan nasional.

Mata pelajaran bahasa Indonesia bertujuan agar peserta didik memiliki kemampuan sebagai berikut: (1) berkomunikasi secara efektif dan efisien sesuai dengan etika yang berlaku, baik secara lisan maupun tertulis. (2) menghargai dan bangga menggunakan bahasa Indonesia sebagai bahasa persatuan dan bahasa negara. (3) memahami bahasa Indonesia dan menggunakannya dengan tepat dan kreatif untuk berbagai tujuan. (4) memahami bahasa Indonesia untuk meningkatkan kemampuan intelektual, serta kematangan emosional dan sosial. (5) menikmati dan memanfaatkan karya sastra untuk memperluas wawasan, memperluas budi pekerti, serta meningkatkan pengetahuan dan kemampuan berbahasa. (6) menghargai dan membanggakan sastra Indonesia sebagai khazanah budaya dan intelektual manusia Indonesia (Fadli et al, 2020; Rambe, 2018; Anzar \& Mardhatillah, 2018). Salah satu aspek penting yang harus dikuasai dengan baik oleh anak sebagai hasil belajar adalah kemampuan mendeskripsikan sesuatu secara linsan dan bercerita secara lisan. Namun, hal ini juga belum meiliki formula yang baik karena kecenderungan di sekolah oleh guru hanya mencoba dan melati anak dengan cara yang sama dengan menguji secara langsung, tidak menggunakan cara-cara yang kreatif 
sehingga menarik. Oleh karena itu penting mengembangkan pembelajaran deskripsi lisan dan cerita lisan pada kelas awal menggunakan metode yang inovatif.

Penelitian tentang pemanfaatan lagu sebagai media pembelajaran khususnya dalam mendeskripsikan benda dan ceriat lisan tampaknya belum dikgunakan secara mendalam. Namun, terdapat beberapa penelitian yang pernah dilakukan dan memiliki kemiripan karakter maupun bidang kajian dengan peneliti ini. (1) Kemampuan Siswa Kelas V SDN. 68 Cangadi Menulis Karangan Deskripsi dengan Bantuan Gambar oleh Aminuddin tahun 2003. (2) Pengembangan Model Pengajaran Menulis Deskriptif Siswa Kelas II SMP Kemala Bayangkari Disamakan di Kota Makassar, oleh Abdul Kadir K. (3) Pemanfaatan Pendekatan Keterampilan Proses dalam Meningkatkan Pembelajaran Menulis Deskripsi Siswa Kelas X SMA Negeri 1 Tamalatea Kabupaten Jeneponto, oleh Muhammad Saleh, tahun 2007.

Dari beberapa penelitian yang telah dilakukan terdahulu tersebut dapat ditarik simpulan umum bahwa proses pembelajaran menulis deskriptif lebih efektif dan bermakna jika menggunakan strategi pembelajaran yang berpusat pada siswa. Keterlibatan siswa secara utuh dalam proses mendeskripsikan nama benda mampu meningkatkan proses dan hasil belajar siswa. Oleh karena itu pentingnya penelitian ini, karena kenyataan banyaknya siswa yang mengalami kesulitan dalam pembelajaran keterampilan mendeskripsikan nama benda dan menceritakan secsuatu secara lisan di kelas awal tingkat sekolah dasar. Pertimbangan selanjutnya, bahwa sepanjang pengetahuan penulis, sampai saat ini belum ada peneliti yang mengungkapkan masalah tersebut pada tingkat sekolah dasar (SD), khususnya pada siswa kelas awal SDN 28 Bontomacinna Kabupaten Bulukumba. Kegiatan yang dilakukan guru selama ini hanya dengan memberikan tugas kepada siswa untuk mendeskripsikan nama benda dengan menggunakan dan bercerita terhadap sesuatu melalui tugas dan ceramah. Para guru di sekolah tersebut belum menemukan cara-cara yang inovatif, kreatif, dan memadai untuk menciptakan proses pembelajaran mendeskripsikan nama benda yang efektif. Suasana pembelajaran masih berlangsung secara monoton, konvensional, dan menjemukan siswa.

Berdasarkan urain-uraian di atas, maka dirumuskan pertanyaan penelitian sebagai berikut.

1. Bagimanakah tingkat kemampuan mendeskripsikan benda sebelum pembelajaran menggunakan lagu kreasi guru siswa kelas I SDN 28 Bontomacinna Kabupaten Bulukumba?

2. Bagimanakah tingkat kemampuan mendeskripsikan benda sesudah pembelajaran menggunakan lagu kreasi guru siswa kelas I SDN 28 Bontomacinna Kabupaten Bulukumba? 
3. Apakah pembelajaran menggunakan lagu kreasi guru efektif dalam meningkatkan kemampuan mendeskripsikan benda siswa kelas I SDN 28 Bontomacinna Kabupaten Bulukumba?

\section{Metode Penelitian}

Penelitian ini merupakan penelitian eksperimen yang berupaya mengungkap data apa adanya melalui eksperimen. Metode eksperimen ini pada prinsipnya adalah mengujicobakan penggunaan media lagu kreasi guru dalam pembelajaran secara serempak tentang deskripsi lisan dan cerita lisan siswa kelas I SDN 28 Bontomacinna Kabupaten Bulukumba. Penelitian ini dilakukan pada satu kelas dan kelas kontrol. Pada kelas eksprimen diberikan pembelajaran dengan menggunakan media lagu sedangkan pada kelas kontrol diberikan pembelajaran konvensional (tidak menggunakan media lagu). Penelitian ini berlokasi di SD SDN 28 Bontomacinna Kabupaten Bulukumba. Subjek dalam penelitian ini adalah seluruh kelas I SDN 28 Bontomacinna Kabupaten Bulukumba tahun pelajaran 2019/2020 berjumlah 28 orang.

Pengumpulan data dalam penelitian ini adalah teknik tes hasil belajar dalam bentuk unjuk kerja untuk mengukur kemampuan siswa mendeskripsikan benda. Prosedur tersebut dilakukan dengan cara setiap siswa tampil mendeskripsikan benda sesuai benda yang diperlihatkan atau disebutkan lalu dinilai sesuai aspek yang telah ditetapkan sebelum penerapan pembelajaran menggunukan lagu kreasi. Keefektifan lagu kreasi jika kemampuan mendeskripsikan benda siswa sebelum dan sesudah mengalami perbedaan signifikan (meningkat) melalui analisis uji t.

Analisis data dalam penelitian ini yaitu data hasil belajar tingkat kemampuan mendeskripsikan benda dianalisis dengan teknik presentasi (\%) dengan rumus: n/Nx100 untuk rentang10-100. Data keefektifan lagu kreasi guru dalam meningkatkan kemampuan mendeskripsikan benda siswa kelas I SDN 28 Bontomacinna Kabupaten Bulukumba menggunakan perhitungan statistik inferensial dengan analisis komputer pada aplikasi komputer dengan data Analisys of t-Test pada Paired Two-Sample Test.

\section{Hasil dan Pembahasan}

\section{Hasil Penelitian}

Adapun data yang dianalisis adalah hasil belajar siswa mendeskripsikan benda sebelum pembelajaran menggunakan lagu kreasi dan mendeskripsikan benda sesudah pembelajaran menggunakan lagu kreasi. Hasil analisis data tersebut terbagi dalam beberapa macam, yaitu skor kemampuan mendeskripsikan benda sebelum pembelajaran menggunakan lagu kreasi dan 
mendeskripsikan benda sesudah pembelajaran menggunakan lagu kreasi, dan data perbandingan atau hasil uji " $t$ " dari kedua data tersebut, serta pengujian hipotesis. Untuk lebih jelasnya diuraikan sebagai berikut.

Tingkat hasil belajar mendeskripsikan benda siswa kelas I Kelas I SDN 28 Bontomacinna Kabupaten Bulukumba sebelum menggunakan lagu kreasi

Data tingkat hasil belajar mendeskripsikan benda siswa kelas I Kelas I SDN 28 Bontomacinna Kabupaten Bulukumba sebelum menggunakan lagu kreasi dapat dilihat pada Tabel 1 berikut.

Tabel 1. Tingkat hasil belajar mendeskripsikan benda siswa kelas I Kelas I SDN 28

\begin{tabular}{cccc}
\multicolumn{4}{c}{ Bontomacinna Kabupaten Bulukumba sebelum menggunakan lagu kreasi } \\
\hline NO & NILAI & F & N X F \\
\hline 1 & 100 & 0 & 0 \\
2 & 90 & 0 & 0 \\
3 & 80 & 3 & 240 \\
4 & 70 & 10 & 700 \\
5 & 60 & 8 & 480 \\
6 & 50 & 5 & 250 \\
7 & 40 & 2 & 80 \\
8 & 30 & 0 & 0 \\
9 & 20 & 0 & 0 \\
10 & 10 & 0 & 0 \\
& JUMLAH & 28 & 1750 \\
\hline
\end{tabular}

Berdasarkan hasil analisis data di atas dapat diketahui:

$\begin{array}{ll}\mathrm{N} & =28 \\ \mathrm{FN} & =1750\end{array}$

Dengan demikian skor rata-rata yaitu:

$$
\begin{aligned}
\text { Rerata } & =\mathrm{F} / \mathrm{N} \\
& =1750 / 28 \\
& =67,31
\end{aligned}
$$

Berdasarkan data di atas dapat diketahuia bahwa, jumlah seluruh nilai seluruh siswa yaitu 1750, sehingga rata-rata nilai hasil belajar mendeskripsikan benda siswa kelas I SDN 28 Bontomacinna Kabupaten Bulukumba sebelum menngunakan lagu kreasi adalah 67,31 dalam rentangan nilai 10-100. Selain itu, berdasarkan hasil analisis data mentah terlihat bahwa nilai perolehan tertinggi adalah 80 dari nilai maksimun 100 sebanyak tiga orang sedangkan nilai terendah adalah 40 yang diperoleh oleh dua orang.

Berdasarkan kategorisasi data, maka dapat dinyatakan bahwa hasil belajar mendeskripsikan benda siswa Kelas I Kelas I SDN 28 Bontomacinna Kabupaten Bulukumba sebelum menggunakan lagu kreasi berada pada kategori sedang. 


\section{Tingkat hasil belajar mendeskripsikan benda siswa kelas I Kelas I SDN 28 Bontomacinna} Kabupaten Bulukumba sesudah menggunakan lagu kreasi

Data tingkat hasil belajar mendeskripsikan benda siswa kelas I Kelas I SDN 28 Bontomacinna Kabupaten Bulukumba sesudah menggunakan teknik konvensional dapat dilihat pada abel 2 berikut.

Tabel 2. Tingkat hasil belajar mendeskripsikan benda siswa kelas I Kelas I SDN 28 Bontomacinna Kabupaten Bulukumba sesudah menggunakan lagu kreasi

\begin{tabular}{cccc}
\hline NO & NILAI & F & N X F \\
\hline 1 & 100 & 0 & 0 \\
2 & 90 & 7 & 630 \\
3 & 80 & 6 & 480 \\
4 & 70 & 8 & 560 \\
5 & 60 & 7 & 420 \\
6 & 50 & 0 & 0 \\
7 & 40 & 0 & 0 \\
8 & 30 & 0 & 0 \\
9 & 20 & 0 & 0 \\
10 & 10 & 0 & 0 \\
& JUMLAH & 28 & 2090 \\
\hline
\end{tabular}

Berdasarkan hasil analisis data di atas dapat diketahui:

$$
\begin{array}{lll}
\mathrm{N} & = & 28 \\
\mathrm{FN} & = & 2090
\end{array}
$$

Dengan demikian skor rata-rata yaitu:

$$
\begin{aligned}
\text { Rerata } & =\mathrm{F} / \mathrm{N} \\
& =2090 / 28 \\
& =74,64
\end{aligned}
$$

Berdasarkan data di atas dapat diketahuia bahwa, jumlah seluruh nilai seluruh siswa yaitu 2090, sehingga rata-rata nilai hasil belajar mendeskripsikan benda siswa kelas I SDN 28 Bontomacinna Kabupaten Bulukumba menngunakan lagu kreasi adalah 74,64 dalam rentangan nilai 10-100. Selain itu, berdasarkan hasil analisis data mentah terlihat bahwa nilai perolehan tertinggi adalah 90 dari nilai maksimun 100 sebanyak tujuh orang dan nilai terendah adalah 60 juga diperoleh oleh tujuh orang.

Berdasarkan analisis sebelumnya, maka dapat dinyatakan bahwa hasil belajar mendeskripsikan benda siswa Kelas I Kelas I SDN 28 Bontomacinna Kabupaten Bulukumba setelah menggunakan lagu kreasi berada pada kategori tinggi.

\section{Uji Hipotesis}

Untuk menentukan keefektifan lagu kreasi pembelajaran mendeskripsikan benda siswa Kelas I Kelas I SDN 28 Bontomacinna Kabupaten Bulukumba maka data hasil belajar 
mendeskripsikan benda sebelun dan sesudah menggunakan lagu kreasi dianalisis dengan menggunakan analisis komputer aplikasi $t$ test paired two sample pada program excel. Adapun ringkasan hasil analisis data pada Tabel 3 berikut.

Tabel 3. Analsis Uji T

\begin{tabular}{lll}
\hline & \multicolumn{1}{c}{ Variable 1 } & \multicolumn{1}{c}{ Variable 2 } \\
\hline Mean & 75,71428571 & 93,21428571 \\
Variance & 156,8783069 & 181,8783069 \\
Observations & 28 & 28 \\
Pearson Correlation & 0,819102009 & \\
Hypothesized Mean & 0 & \\
Difference & 27 \\
$d f$ & 11,75686525 & \\
$t$ Stat & $1,97924 \mathrm{E}-12$ & \\
$P(T<=t)$ one-tail & 1,703288446 & \\
$t$ Critical one-tail & $3,95849 \mathrm{E}-12$ & \\
$P(T<=t)$ two-tail & 2,051830516 & \\
$t$ Critical two-tail &
\end{tabular}

Berdasarkan ringkasan hasil pengolahan dan penyajian data, maka dapat dipaparkan pengujian hipotesis bahwa hasil analisis data diperoleh nilai "t" stat adalah 11,75686525 sedangkan nilai t Critical two-tail adalah 1,703288446 maka dapat dijelaskan nilai stat lebih besar daripada nilai t Critical two-tail (stat: 11,75686525 > t Critical two-tail: 1,703288446) pada taraf signifikan 0,05 . Hal menunjukkan bahwa hipotesis nol yang berbunyi: "Pembelajaran menggunakan lagu kreasi guru tidak efektif dalam meningkatkan kemampuan mendeskripsikan benda siswa kelas I SDN 28 Bontomacinna Kabupaten Bulukumba "ditolak". Hipotesis alternatif berbunyi: Pembelajaran menggunakan lagu kreasi guru efektif dalam meningkatkan kemampuan mendeskripsikan benda siswa kelas I SDN 28 Bontomacinna Kabupaten Bulukumba "diterima". Dengan demikian, dapat dikemukakan bahwa pembelajaran menggunakan lagu kreasi guru efektif dalam meningkatkan kemampuan mendeskripsikan benda siswa kelas I SDN 28 Bontomacinna Kabupaten Bulukumba.

\section{Pembahasan}

Berdasarkan dari analisis data dalam penelitian, bahwa hasil belajar mendeskripsikan benda siswa kelas I Kelas I SDN 28 Bontomacinna Kabupaten Bulukumba sebelum menggunakan lagu kresi adalah 67,31 dalam rentangan nilai 10-100. Jika dikaitkan dengan klasifikasi penilaian, maka klasifikasi hasil belajar dinyatakan bahwa hasil belajar mendeskripsikan benda siswa kelas I Kelas I SDN 28 Bontomacinna Kabupaten Bulukumba sebelum menggunakan lagu kresi berada pada kategori sedang. Selain itu, data penelitian dapat dijelaskan bahwa tingkat hasil belajar mendeskripsikan benda siswa kelas I Kelas I SDN 28 
Bontomacinna Kabupaten Bulukumba setelah menggunakan lagu kreasi adalah 74,64 dalam rentangan nilai 10-100. Jika dikaitkan dengan klasifikasi hasil belajar maka dapat dinyatakan bahwa hasil belajar mendeskripsikan benda siswa Kelas I SDN 28 Bontomacinna Kabupaten setelah Bulukumba menggunakan lagu kreasi meningkat menjadi kategori tinggi.

Sementara itu, data pada hasil analisis keefektifan dalam uji $t$, menunjukkan nilai " $t$ " stat adalah 11,75686525 sedangkan nilai $t$ Critical two-tail adalah 1,703288446 maka dapat dijelaskan nilai stat lebih besar daripada nilai $t$ Critical two-tail (stat: 11,75686525 > t Critical two-tail: 1,703288446) pada taraf signifikan 0,05, yang berarti lagu kreasi efektif dalam meningkatkan hasil mendeskripsikan benda Kelas I SDN 28 Bontomacinna Kabupaten Bulukumba pada taraf kepercayaan 95\%. Berdasarkan hasil penelitian ini dapat dipahami bahwa salah satu alternatif mengefektifkan pembelajaran mendeskripsikan benda khusnya di kelas I sekolah dasar adalah menggunakan lagu kreasi sebagai media. Hal ini telah dibuktikan dengan ujicoba pada siswa Kelas I SDN 28 Bontomacinna Kabupaten Bulukumba yang menunjukkan efektif.

Pembelajaran mendeskripsikan benda yang selama ini dianggap sulit karena pada umumnya guru hanya langsung menyuruh siswa mendeskripsikan benda setelah meberi contoh membuat tidak menarik dan tidak memberi kesan medalam serta tidak merangsang imajinasi anak dalam mendetailkan objek deskripsi. Jika dilatihkan dengan menggunakan lagu kresi guru akan menjadi lebih mudah bagi anak mendeskripskan benda karena terbantu dalam mendetailkan objek sebagai hasil imajinasi dalam lagu yang mana dalam lagu dapat membuat anak menangkap makna subtansi secara cepat.

Hasil penelitian di atas sesuai konsep yang dikemukakan oleh Ahsin (2016) bahwa keterampilan menulis karangan narasi dapat dibantu dengan media audiovisual dan metode quantum learning. Padangan lain tentang penelitian ini adalah DePorter et al. (2010) menegaskan bahwa rangsangan lagu dalam belajar akan memberi daya ingat pada jangka panjang bagi sesorang dan imaji nasi mereka berkembang dengan luas. Hasil penelitian ini sejalan dengan hasil penelitian Idris et al. (2014) yang menegaskan bahwa kemampuan menulis deskripsi siswa sangat dibantu oleh adanya rangsangan dalam audio yang mendetailkan objek. Senada dengan hal tersebut, Permanasari (2017) melaporkan hasil penelitian bahwa kemampuan menulis teks deskripsi siswa kelas VII SMP Negeri 1 Sumber Jaya Lampung Barat efektif menggunakan teknik investigasi terhadap objek yang akan dideskripsikan.

Penelitian yang menggunakan lagu untuk meningkatkan kemampuan mendeskripsikan benda ini tentu memiliki keterabatasan antara lain: (1) sampel penelitian hanya sedirkit sehingga generalisasinya terbatas, (2) variabel penelitian ini hanya dua dan waktu penelitian 
cukup singkat sehingga detail tentang aspek lainnya aselain hasil belajar tidak diungkapkan, (3) penelitian ini hanya bersifat kuantitatif sehingga hanya variabel yang diteliti yang diungkapkan, tidak diungkapkna kelemahan kelebihan, sebagainya.

\section{Kesimpulan}

Berdasarkan rumusan masalah penelitian yang diajukan, serta hasil penelitian yang didasarkan pada analisis data dan pengujian hipotesis maka dapat disimpulkan bahwa:

a. Tingkat hasil belajar mendeskripsikan benda siswa Kelas I SDN 28 Bontomacinna Kabupaten Bulukumba sebelum menggunakan lagu kreasi adalah rata-rata 63,31 dalam rentangan nilai 10-100 dengan kategori sedang.

b. Tingkat hasil belajar mendeskripsikan benda siswa kelas I Kelas I SDN 28 Bontomacinna Kabupaten Bulukumba sesudah menggunakan lagu kreasi adalah ratarata 74,64 dalam rentangan nilai 10-100 dengan kategori tinggi.

c. Pembelajaran menggunakan lagu kreasi guru efektif dalam meningkatkan kemampuan mendeskripsikan benda siswa kelas I SDN 28 Bontomacinna Kabupaten Bulukumba dengan nilai $t$ Critical two-tail (stat: $11,75686525>t$ Critical two-tail: 1,703288446) pada taraf signifikan 0,05 .

\section{DAFTAR PUSTAKA}

Abidin, Y., Mulyati, T., \& Yunansah, H. (2021). Pembelajaran Literasi: Strategi Meningkatkan Kemampuan Literasi Matematika, Sains, Membaca, dan Menulis. Bumi Aksara.

Ahmad Susanto, M. P. (2016). Teori belajar dan pembelajaran di sekolah dasar. Kencana.

Ahsin, M. N. (2016). Peningkatan keterampilan menulis karangan narasi dengan menggunakan media audiovisual dan metode Quantum Learning. Refleksi Edukatika: Jurnal Ilmiah Kependidikan, 6(2).

Anggraini, V. (2019). Stimulasi Keterampilan Menyimak terhadap Perkembangan Anak Usia Dini. Raudhatul Athfal: Jurnal Pendidikan Islam Anak Usia Dini, 3(1), 30-44.

Anzar, S. F., \& Mardhatillah, M. (2018). Analisis Kesulitan Belajar Siswa Pada Pembelajaran Bahasa Indonesia di Kelas V SD Negeri 20 Meulaboh Kabupaten Aceh Barat Tahun Ajaran 2015/2016. Bina Gogik: Jurnal Ilmiah Pendidikan Guru Sekolah Dasar, 4(1).

Budiman, A. (2018). ANALISIS ASPEK SOSIAL BUDAYA DALAM CERITA RAKYAT "ENYENG" DI DESA CIPANCAR SEBAGAI BAHAN PEMBELAJARAN BAHASA DAN SASTRA INDONESIA DI SMA. JESA-Jurnal Edukasi Sebelas April, 2(1), 1-9.

Dewantara, I. P. M. (2012). Identifikasi faktor penyebab kesulitan belajar keterampilan berbicara siswa kelas VIIE SMPN 5 Negara dan strategi guru untuk mengatasinya. Jurnal 
Pendidikan Dan Pembelajaran Bahasa Indonesia, 1(2).

DePorter, B., Reardon, M., \& Singer-Nourie, S. (2010). Quantum teaching: mempraktikkan quantum learning di ruang-ruang kelas. Kaifa.

Diari, K. P. Y., \& Putra, M. S. (2019). Menumbuhkan Literasi Bahasa Melalui Budaya Mesatua Pada Siswa Sekolah Dasar. Prosiding Nasional, 109-115.

Eti, E. (2018). Increasing imagination creativity students' of indonesian langauge learning through cloze dilition technique (tcd) in poetry at sixth grade students' in sd negeri no. 27 sungai tawar kecamatan koto xi tarusan. Jurnal Ilmiah Pendidikan Scholastic, 2(1), 12-19.

Fadli, R. I., Nugraha, A. S., Raharjo, R. P., \& Sulton, A. (2020). Model Pembelajaran Inovatif Guru SMA Abdul Hadi dengan Strategi Literasi. ABIDUMASY Jurnal Pengabdian kepada Masyarakat, 1(1), 1-12.

Hum, Z. M. (2015). PRINSIP-PRINSIP DAN LANDASAN PEMBELAJARAN BAHASA INDONESIA. Jurnal Ilmiah “RESEARCH SAINIS” Vol, l(1).

Idris, Y., Thahar, H. E., \& Juita, N. (2014). Peningkatan Keterampilan Menulis Karangan Deskripsi Melalui Metode Discovery Dengan Menggunakan Media Gambar Mahasiswa Prodi Pendidikan Bahasa Dan Sastra Indonesia Ta 2011/2012 Universitas Ekasakti Padang. Bahasa, Sastra, dan Pembelajaran, 2(3).

Khair, U. (2018). Pembelajaran Bahasa Indonesia dan Sastra (BASASTRA) di SD dan MI. ARRIAYAH: Jurnal Pendidikan Dasar, 2(1), 81.

Marhaeni, A. A. I. N. (2015). Asesmen autentik dan pendidikan bermakna: implementasi kurikulum 2013. JPI (Jurnal Pendidikan Indonesia), 4(1).

Nur'aini, H. I. M., Saddhono, K., \& Ulya, C. (2015). Implementasi kurikulum 2013 pada pembelajaran menulis teks eksposisi (studi kasus di kelas $\mathrm{x}$ smk negeri 1 karanganyar). BASASTRA, 3(3).

Nurjanah, E., \& Rahmawati, V. V. (2020). PENGARUH PENGGUNAAN METODE STUDENT FACILITATOR AND EXPLAINING TERHADAP PENCAPAIAN HASIL BELAJAR SISWA PELAJARAN BAHASA INDONESIA. Jurnal Pendidikan Dasar Islam, 2(1), 1-20.

Permanasari, D. (2017). Kemampuan menulis teks deskripsi siswa kelas VII SMP Negeri 1 Sumber jaya Lampung Barat. Jurnal Pesona, 3(2).

Rambe, R. N. K. (2018). Penerapan strategi index card match untuk meningkatkan hasil belajar siswa pada mata pelajaran bahasa indonesia. Jurnal tarbiyah, 25(1).

Samsudin, A. (2012). Peningkatan Kemampuan Menulis Eksposisi Berita Dan Menulis Eksposisi Ilustrasi Siswa Kelas V Melalui Model Pembelajaran Kooperatif Terpadu Membaca Dan Menulis< br. Jurnal Penelitian Pendidikan, 13(2), 1-11.

Silaswati, D., Bulan, D. R., SS, M., \& Hermawan, D. (2019). MODEL PEMBELAJARAN 
APRESIASI KAJIAN SASTRA TERPADU UNTUK PENGUASAAN EMPAT ASPEK KETERAMPILAN BERBAHASA. METAMORFOSIS| Jurnal Bahasa, Sastra Indonesia dan Pengajarannya, 12(2), 26-39.

Sumarwati, S. (2017). Keefektifan Model Pembelajaran Tata Bahasa dan Keterampilan Berbahasa Secara Terpadu dengan Pendekatan Focus on Form. Jurnal Pendidikan dan Pembelajaran (JPP), 23(2), 096-104.

Sumarwati, S., Anindyarini, A., \& Fuady, A. (2014). Pembelajaran Kaidah Bahasa Indonesia Dan Keterampilan Berbahasa Secara Terpadu Dengan Pendekatan Focus On Form Pada Siswa Sekolah Menengah Pertama. Litera, 13(1).

Susilo, S. V., \& Ramdiati, T. (2019). Penerapan Model Multiliterasi Untuk Meningkatkan Keterampilan Menulis Karangan Persuasi Pada Mata Pelajaran Bahasa Indonesia Di Sekolah Dasar. Jurnal Cakrawala Pendas, 5(1), 280137.

Suwandi, S., \& Rohmadi, M. (2013). Pendidikan Multikultural Dalam Buku Ajar Bahasa Dan Sastra Indonesia Untuk Siswa Sekolah Menengah Pertama Di Surakarta. Widyaparwa, 4l(1), 29-40.

Yaumi, M. (2017). Prinsip-prinsip desain pembelajaran: Disesuaikan dengan kurikulum 2013 edisi Kedua. Kencana. 